\title{
The Transition towards Sustainable Supply Chain Management: An Empirical Study
}

\author{
Amrita Singh ${ }^{1,}$ Parul Agarwal ${ }^{1}$, Saurav Dixit ${ }^{2 *}$, Sonali Singh ${ }^{3}$, and Sanjai Sahai ${ }^{4}$ \\ ${ }^{1}$ ABES Engineering College, Ghaziabad, India \\ ${ }^{2}$ RICS School of Built Environment, Amity University, Noida, India \\ ${ }^{3}$ Jaipuria Institute of Management, Noida, India \\ ${ }^{4}$ ABS, Amity University Noida, India
}

\begin{abstract}
In the last one decade, the concept of SSCM, green and circular economy has been developed we have seen the synchronization of green and sustainable supply chain management practices by the firms to reduce the impact over the environment in developed countries as well as in developing countries. The intent of the author is to identify benefits of the new practices. The methodology used for the study is to analyze the available literature and identify the main attributes and prioritize using relative importance index. The study shall perceive direct and indirect benefits from the community and the surroundings. The study provides insight to the topic and to validate the results of the research same type of study to complete in the other regions of the country to have a clear and better understanding of the topic is suggested.
\end{abstract}

Keywords: Sustainable Supply chain. Green, Circular economy, Empirical study

\section{Introduction}

In the present worldwide commercial centre, offering an item is once in a while simpler than influencing the items to reach to clients. Organizations may need to choose the ideal approach to store, handle and move their items and administrations with the goal that they are accessible to clients in the correct collections, at the ideal time and at the opportune place. Store network majorly affects both client enjoyment and costs, making organizations operation successful. Organizations are putting accentuation on store network for a few reasons [1]. To begin with, making the channel accomplices both upstream and downstream maintainable, increasing upper hands, cost sparing to both organization and clients, blast in item assortment has made a requirement for enhanced inventory network. At last, logistics influence the earth and an organization's natural manageability endeavours. Transportation, warehousing, bundling and different logistics capacities are ordinarily the significant production network supporters of the association's ecological impression. In the meantime, they additionally give a standout amongst the most zones for cost funds. So building up a feasible green store network isn't just being socially and naturally dependable, it can likewise be produced.

Supportability has turned into a critical issue since it reviews financial viewpoints, as well as natural and social contemplations that the organizations ought to take after. In this paper, these three measurements of supportability have been taken in particular condition, economy and social variables. It is imperative to consolidate condition and social variables for contending in changing and turbulent condition to keep up an upper hand. Nature execution "assesses and measures the degree to which firms decrease their ecological effect through a diminishment in risky materials, asset utilization, ozone-harming substance outflows, squander transfer and waste drainage. The monetary execution getting from ecologically neighbourly items is estimated by standard measurements, for example, R.O.I, piece of the overall industry development, benefits development and benefits development rate. The measure of the social execution can be identified with 'human' centred nature of the field.

In the accompanying table, we display a couple of meanings of logistics administration, inventory network administration and Sustainable store network administration. The expectations to utilize these definitions by creators is to better clarify and grandstand the contrast between these capacities and to present a development of SSCM.

\subsection{Supply chain management}

" Supply chain administration is the coordination of key process from end client through unique providers that 
gives items, administrations and data that include an incentive for clients and other partners" The Global Supply Chain Forum

"SCM as - fruitful coordination and a mix of each one of those exercises related to moving merchandise from the crude materials organize all the way to the finished client, for supportable upper hand. This incorporates exercises like frameworks administration, sourcing and acquirement, creation booking, arrange preparing, stock administration, transportation, warehousing and client benefit" [2]

"Inventory network administration is characterized as the foundational, key coordination of the conventional business capacities and the strategies over these business capacities inside a specific organization and crosswise over organizations inside the production network, for the reasons for enhancing the long haul execution of the individual organizations and the store network as a whole. [3].

Store network administration (SCM) is the oversight of materials, data, and funds as they move in a procedure from provider to maker to distributer to retailer to customer. Inventory network administration includes organizing and coordinating these streams both inside and among organizations.

\subsection{Logistics management}

"Arranging, executing and controlling the physical stream of materials, last products and related data from purposes of inception to purposes of utilization to meet client prerequisite at a benefit." Councils of logistics administration [4].

Logistics include "dealing with the stream of things, data, money and thoughts through the coordination of production network forms and through the vital expansion of place, period and example esteems." MIT Center for Transportation and Logistics.

Logistics administration is that piece of production network administration that designs, executes, and controls the proficient, viable forward and switch stream and capacity of merchandise, benefits and related data between the purpose of root and the purpose of utilization with a specific end goal to meet clients' necessities. - Council of inventory network administration experts.

\subsection{Sustainable supply chain management}

"The maintainable of production network administration requires a more extensive vision and must feature the financial natural and social parts of business hone"- "The Strategic, straightforward combination and accomplishment of an associations social, condition and monetary objectives in the fundamental coordination of key between hierarchical business process for enhancing the long haul financial execution of the individual and its supply chain."

"A feasible production network is the one that performs well on both customary measures of benefit and misfortune and additionally on an extended conceptualization of execution that incorporates both social and common measurements".
"The administration of store network operations, assets, data and supports keeping in mind the end goal to augment the inventory network productivity while in the meantime limiting the natural effects and expanding the social well-being".

\section{Literature review}

Production network administration infers the contribution of various performing artists in esteem creation, to energize the foundation of connections that are an imperative component for contending in a changing and turbulent condition. It is indispensable to join natural and social administration rehearses into the entire inventory network keeping in mind the end goal to keep up an upper hand.

Maintainability is a multidimensional develop that extends the financial primary concern idea, which concentrates on the productive utilization of assets and on accomplishing an arrival on speculations, by including social contemplations and advancing more prominent biological obligation. Given that each organization is a piece of a more extensive system and isn't an island in the present business world, there is an incredible significance in relationship administration that requires acting past organization limits. As of late, the method for picking up an upper hand has changed the structure of the opposition, with the goal that opposition between organizations has transformed into between production network rivalries.

The expanding impact of maintainability in inventory network administration and operations practices can likewise be credited to the way that, notwithstanding expanded requests of solid monetary execution, associations are presently considered in charge of the ecological and social execution by significant partners. Furthermore, practical store network administration has turned into a vital procedure empowering firms to make an upper hand.

The necessity to take a comprehensive perspective of the entire item inventory network is a central advance for setting up greener and more maintainable generation frameworks, in view of re-utilizing and reproducing materials. These frameworks could likewise prompt the production of new focused plans of action. Such models could be founded on the worldview of support tosupport, empowering the utilization of crude materials known as specialized and organic supplements, which don't negatively affect the earth, have an altogether useful effect upon natural frameworks and come back to the biological community without medicines [5].

Moreover, without a moment to spare (JIT) supply involves providers creating and conveying to manufacturers right amount at an ideal time with nonstop and predictable conformance to execution particulars. JIT has turned out to be urgent for survival and accomplishment in turbulent business conditions that depicts the larger part of the business scene today. Electronic acquisition (e-acquirement) alludes to a virtual buying application that helps firms lessening their obtaining cost. 
Both among business practitioners and researchers, it has been noted that sustainable supply chain management (SSCM) has increased its importance in companies together with the rising demand for sustainability. Research results show that companies are expected to increasingly pay interest on their supply chain, and not only to their direct suppliers but also to parties beyond their direct reach ([6]-[9]. The supply chains have grown largely due to globalization and outsourcing [10]. Currently, the number of companies who possess the knowledge of sustainability issues from their whole supply chain is small, which makes this research topic especially relevant as the majority of companies will soon be faced with the need of responding to growing sustainability demands of their stakeholders. The implementation of sustainability initiatives within the first tiers of suppliers is already quite widely researched. The success in implementation is said to derive from common goals and aligned initiatives within different tiers. The complexity of the network and industry is also taken into consideration. What is especially said to be lacking research, is analyzing the implementation within multiple companies in a supply chain [6], [8], [11]-[15].

\subsection{Objectives of the study}

I. To determine the factors influencing the companies to adopt sustainable supply chain management practices. II. To prioritise the attributes on the basis of their relative importance index on various companies in the transition towards SSCM.

\section{Research Methodology}

For this research paper, a questionnaire survey method has been used to discover the Benefits of synchronizing sustainability and lean Construction in Indian Construction industry. First the perception of the professionals working in the industry on the implementation of Sustainability and Lean Construction has been analyzed through the Relative importance index (RII) and secondly the attributes identified through literature review as the Benefits of synchronizing sustainability and lean Construction were analyzed using Relative importance index (RII), relative importance index (Rii) was applied to prioritise the severity of the factors" [2] [3] [4] and other techniques.

Quantitative research methodology is adopted for the study. The data is collected using structured questionnaire survey. Primary data has been collected for the study because of non-availability of secondary data on the said title. The convenience sampling technique is used to collect the data from the known and easily approachable respondents. The questionnaire is shared with 500 professionals working in different segments of the economy including but not limited to manufacturing, production, suppliers, customers, construction, energy, and others sectors. A total of 120 valid responses were received with a response rate of $24 \%$.

The structured questionnaire is divided into three parts: the first portion has information about the topic and general study that is to be conducted, the second part is the questionnaire itself and the last portion consists the feedback and any suggestion for the study by the respondents. The respondents were asked to rate the questions on the Likert scale of 1-5 given against each question.

\subsection{Reliability analysis}

Dependability analysis is needed to check the consistency of the model after some time, and Cronbach's alpha test was the best way to check the reliability of the data collected through questionnaire [5]. The value of Cronbach's alpha for this study is 0.85 which is considered to be superior.

Table 1 Reliability analysis

\begin{tabular}{|l|l|}
\hline Attributes Cronbach's alpha $(\mathrm{C} \alpha)$ & \\
\hline Attributes in factor 1 & 0.83 \\
\hline Attributes in factor 2 & 0.84 \\
\hline Attributes in factor 3 & 0.82 \\
\hline Attributes in factor 4 & 0.86 \\
\hline \multicolumn{2}{|c|}{ Attributes selected for the } \\
study & 0.85 \\
\hline
\end{tabular}

Table 2 Kaiser-Meyer-Olkin measure of sampling adequacy

\begin{tabular}{|l|l|}
\hline $\begin{array}{l}\text { Kaiser-Meyer-Olkin measure of } \\
\text { sampling adequacy }\end{array}$ & 0.813 \\
\hline $\begin{array}{l}\text { Bartlett's test of sphericity } \\
\text { Approx }_{\chi} 2\end{array}$ & 3985.81 \\
\hline Degrees of freedom & 1540 \\
\hline Significance & 0.000 \\
\hline
\end{tabular}

\subsection{Relative importance index}

The received responses by the respondents were summarised in an Excel data sheet and the data analysed using SPSS software. Relative importance indices (RII) is performed to determine the priority of the significant factors and then followed by Reliability analysis performed to check the consistency of the data received. Rii $=\frac{\sum_{:=1}^{5} 1^{*} n_{2}}{5 \mathrm{~N}}$

$\mathrm{r}$ is the rating on a Likert scale (1-5) as for the impact on construction efficiency for a specific element influencing construction profitability, $\mathrm{nr}$ is the number of respondents providing a specific Likert scale rating $\mathrm{r}, \mathrm{N}$ is the aggregate number of respondents to a specific question [6][4], [16], [17].

The value given to the Likert scale rating is as follows:

1. No effect ( or no opinion)

2. Less effect (no or minimal effect)

3. Minor effect (minor problem)

4. Serious effect (medium problem)

5. Very serious effect (major problem 
Table 3 Relative importance index

\begin{tabular}{|c|c|c|c|c|}
\hline $\begin{array}{l}R a \\
n k\end{array}$ & $\begin{array}{l}\text { Total } \\
\text { respo } \\
\text { nses }\end{array}$ & $\begin{array}{l}\text { Tot } \\
\text { al } \\
\text { scor } \\
e\end{array}$ & $R I I$ & Attribute name \\
\hline 1 & 120 & 542 & 0.90 & Raw materials management \\
\hline 2 & 120 & 512 & 0.85 & Cost saving \\
\hline 3 & 120 & 491 & 0.69 & Customer delight \\
\hline 4 & 120 & 490 & 0.69 & Social responsibility \\
\hline 5 & 120 & 480 & 0.69 & Reduce/recycle/reuse \\
\hline 6 & 120 & 457 & 0.68 & Environmental benefits \\
\hline 7 & 120 & 454 & 0.68 & Competitive advantage \\
\hline 8 & 120 & 454 & 0.67 & $\begin{array}{l}\text { Reduce carbon footprint } \\
\text { emission }\end{array}$ \\
\hline 9 & 120 & 451 & 0.67 & Inventory control \\
\hline 10 & 120 & 446 & 0.67 & Helps to circular economy \\
\hline 11 & 120 & 445 & 0.67 & $\begin{array}{l}\text { management of unfinished } \\
\text { and finished sections }\end{array}$ \\
\hline 12 & 120 & 435 & 0.67 & $\begin{array}{l}\text { Proper management of } \\
\text { finished goods }\end{array}$ \\
\hline 13 & 120 & 434 & 0.67 & $\begin{array}{l}\text { Management of labour, } \\
\text { scientific and technical } \\
\text { personnel -helping in } \\
\text { reducing carbon emission. }\end{array}$ \\
\hline 14 & 120 & 426 & 0.66 & $\begin{array}{l}\text { management of late order } \\
\text { delivery to the customer }\end{array}$ \\
\hline 15 & 120 & 419 & 0.66 & $\begin{array}{l}\text { management of returned } \\
\text { goods from customer }\end{array}$ \\
\hline 16 & 120 & 418 & 0.66 & $\begin{array}{l}\text { Management of credits for } \\
\text { incorrectly filled or late } \\
\text { deliveries from the } \\
\text { supplier. }\end{array}$ \\
\hline 17 & 120 & 414 & 0.65 & $\begin{array}{l}\text { product flow facility } \\
\text { structure }\end{array}$ \\
\hline 18 & 120 & 392 & 0.65 & information flow structure \\
\hline 19 & 120 & 391 & 0.65 & $\begin{array}{l}\text { understanding of culture } \\
\text { and consumerism }\end{array}$ \\
\hline 20 & 120 & 382 & 0.65 & $\begin{array}{l}\text { Proper management of } \\
\text { goods returned to suppliers }\end{array}$ \\
\hline 21 & 120 & 379 & 0.65 & $\begin{array}{l}\text { Proper management of } \\
\text { machines, material } \\
\text { handlers, tools etc. which } \\
\text { helps in reducing carbon } \\
\text { emission }\end{array}$ \\
\hline 22 & 120 & 374 & 0.65 & $\begin{array}{lr}\text { management } & \text { of } \\
\text { warehouses, storage and } \\
\text { retrieval system }\end{array}$ \\
\hline 23 & 120 & 358 & 0.64 & $\begin{array}{l}\text { management } \begin{array}{r}\text { of } \\
\text { transportation } \\
\text { shipments, } \\
\text { engage truck, rail transport }\end{array} \\
\text { air-cargo, }\end{array}$ \\
\hline
\end{tabular}

\subsection{Most significant benefits of the transformation to SSCM}

The most significant benefits through the transition towards SSCM are raw material management, cost saving, customer delight, social responsibility and reduce/recycle/reuse having a relative importance index value of $0.9,0.85,0.69,0.69$, and 0.69 respectively

\subsection{Significant benefits of the transformation to} SSCM

The significant benefits through the transition towards SSCM are environmental benefits, competitive advantages, reduced carbon footprints, inventory control and helps in circular economy having a relative importance index value of $0.68,0.68,0.67,0.67$, and 0.67 respectively.

\subsection{Factor analysis}

Factor analysis is used to reduce the number of dimensions in the data and provide a more clustered output on the basis of co-variance between different attributes. The factor analysis is performed using SPSS 18 for this study. A total of four factors was formed using the software are economic, social, environmental, and logistics explained a variance of $23.1 \%, 17.2 \%$, $14.3 \%$, and $8.67 \%$ respectively.

Table 4 Factor analysis

\begin{tabular}{|c|c|c|}
\hline Factor/variable name & $\begin{array}{l}\text { Factor } \\
\text { loading }\end{array}$ & $\begin{array}{l}\text { \%age of } \\
\text { variance } \\
\text { explained }\end{array}$ \\
\hline Factor 1- Economic & & $23.1 \%$ \\
\hline Cost saving & 0.61 & \\
\hline product flow management & 0.6 & \\
\hline information flow management & 0.56 & \\
\hline $\begin{array}{l}\text { Proper management of machines, } \\
\text { material handlers, tools etc. which } \\
\text { helps in reducing carbon } \\
\text { emission }\end{array}$ & 0.51 & \\
\hline $\begin{array}{l}\text { management of warehouses, } \\
\text { storage and retrieval system }\end{array}$ & 0.55 & \\
\hline Factor 2- Social & & $17.2 \%$ \\
\hline Customer delight & 0.59 & \\
\hline Social responsibility & 0.57 & \\
\hline Competitive advantage & 0.55 & \\
\hline $\begin{array}{l}\text { understanding of culture and } \\
\text { consumerism }\end{array}$ & 0.53 & \\
\hline Factor 3- Environmental & & $14.3 \%$ \\
\hline Reduce/recycle/reuse & 0.58 & \\
\hline Environmental benefits & 0.50 & \\
\hline Reduce carbon footprint emission & 0.48 & \\
\hline $\begin{array}{l}\text { Management of labour, scientific } \\
\text { and technical personnel -helping } \\
\text { in reducing carbon emission. }\end{array}$ & 0.48 & \\
\hline Factor 4- Logistics & & $8.67 \%$ \\
\hline $\begin{array}{lll}\begin{array}{l}\text { Inventory } \\
\text { management }\end{array} & \text { control and } & \\
\end{array}$ & 0.62 & \\
\hline Helps to a circular economy & 0.59 & \\
\hline $\begin{array}{l}\text { management of unfinished and } \\
\text { finished sections }\end{array}$ & 0.59 & \\
\hline $\begin{array}{l}\text { Proper management of finished } \\
\text { goods }\end{array}$ & 0.49 & \\
\hline Total \%age of variance explained & & $63.3 \%$ \\
\hline
\end{tabular}




\section{Discussion and conclusion}

The study reveals that the average value of reliability analysis for all the attributes is above 0.5 i.e. all the attributes selected for the study had a significant and valuable perceived benefit. The most important benefits through the transition towards SSCM are raw material management, cost saving and consumer delight. Sustainable supply chain management has lately received large research interest in different fields. This research area has developed during the last decades and can be approached from many different perspectives. Some studies of sustainability implementation in supply chains are focusing on the environmental issues [8], [13], [18]-[21] whereas others have a wider perspective for sustainability covering also social responsibility [8], [22], [23]. A major categorization has been made by the motivations of the implementation whether basing on demand by a more powerful party in the supply chain or driven in collaboration.

\section{Limitations of the study}

The study is conducted using structured questionnaire survey and collection of primary data. The received responses are 120 considered for this study is comparatively small to generalise the findings to the larger scale. It is recommended to conduct a similar kind of study in different regions of the country to have a better understanding of the SSCM.

\section{References}

[1] A. K. Pandey, S. Dixit, S. Bansal, S. Saproo, and S. N. Mandal, Int. J. Civ. Eng. Technol., vol. 8, no. 10, pp. 87-98, 2017.

[2] A. K. Pandey, S. Dixit, S. Bansal, S. Saproo, and S. N. Mandal, Int. J. Civ. Eng. Technol., vol. 8, no. 10, 2017.

[3] S. Dixit, S. N. Mandal, A. Sawhney, and S. Singh, Int. J. Civ. Eng. Technol., vol. 8, no. 8, 2017.

[4] S. Dixit, S. N. Mandal, A. Sawhney, and S. Singh, Int. J. Civ. Eng. Technol., vol. 8, no. 8, pp. 623-636, 2017.

[5] M. C. Cooper, D. M. Lambert, and J. D. Pagh, Int. J. Logist. Manag., vol. 8, no. 1, pp. 1-14, 1997.

[6] B. J. Mariadoss, T. Chi, P. Tansuhaj, and N. Pomirleanu, J. Bus. Res., vol. 69, no. 9, pp. 3406-3414, 2016.

[8] S. Seuring and M. Müller, J. Clean. Prod., vol. 16, no. 15, pp. 1699-1710, 2008.

[9] B. Logistics, no. January, 2018.

[10] S. Nurkka, "Sustainable multi-tier supply chain management Case from Finnish food industry," 2017.

[11] T. F. Burgess, P. Grimshaw, L. Huaccho Huatuco, and N. E. Shaw, Int. J. Oper. Prod. Manag., vol. 37, no. 7, pp. 898-926, 2017.
[12] L. D. Fredendall, "Supply chain management practices and intellectual property protection in China," 2016.

[13] M. E. Torabizadeh, M. Y. Y. Noordin, and M. S. S. Awaluddin, Mater. Ind. Manuf. Eng. Res. Adv. 1.1, vol. 845, no. May, pp. 516-520, 2014.

[14] G. Wang, A. Gunasekaran, E. W. T. Ngai, and T. Papadopoulos, Int. J. Prod. Econ., vol. 176, pp. 98-110, 2016.

[15] A. Intelligence et al., "About the Tutorial Disclaimer \& Copyright."

[16] S. Singh, A. Bala, S. Dixit, and D. Varshney, Int. J. Civ. Eng. Technol., vol. 9, no. 1, 2018.

[17] A. Sao, S. Singh, S. Dixit, A. K. Pandey, and S. Singh, Int. J. Mech. Eng. Technol., vol. 8, no. 10, 2017.

[18] S. Vasković, P. Gvero, V. Medaković, and V. Halilović, Sustain. Supply Chain Manag., no. June, 2016.

[19] S. K. Srivastava, Int. J. Manag. Rev., vol. 9, no. 1, pp. 53-80, 2007.

[20] G. Saththasivam and Y. Fernando, "Integrated Sustainable Supply Chain Management," no. April, pp. 218-233, 2017.

[21] E. Tatoglu, E. Bayraktar, I. Golgeci, S. C. L. Koh, M. Demirbag, and S. Zaim, Int. J. Logist. Res. Appl., vol. 19, no. 3, pp. 181-199, 2016.

[22] D. M. Lambert, M. C. Cooper, and J. D. Pagh, International Journal of Logistics Management, vol. 9, no. 2. pp. 1-19, 1998.

[23] M. A. Saeed and I. Waseek, 2017. 